\section{Experimental caprine coccidiosis: the pattern of changes in antioxidant micronutrients and vitamins}

\author{
Ehsan Rakhshandehroo, 1 \\ Seyed Mostafa Razavi, 1 Saeed Nazifi² \\ Departments of 1Pathobiology and \\ ${ }^{2}$ Clinical Studies, School of Veterinary \\ Medicine, Shiraz University, Iran
}

\begin{abstract}
This study aimed at investigating the status of non-enzymatic antioxidant agents during experimental caprine coccidiosis. A total of 20 newborn kids were selected and allocated into 2 (diseased and healthy) groups. Ten of the kids were infected with sporulated oocysts of the most pathogenic species of Eimeria and ten served as controls. Blood samples were taken at 0 (before inoculation), 3, 7, 14, 21, 28 and 35 days post infection (dpi) and the concentrations of antioxidant trace elements, antioxidant vitamins and ceruloplasmin were measured. Our data showed remarkable reductions in serum concentrations of some antioxidant trace elements (zinc, manganese and selenium) and vitamins (vitamin C) in the diseased kids, however, significant increases were observed in the serum level of ceruloplasmin in infected animals. These alterations became more prominent at 14 to 21 dpi. These observations suggest that Eimeria parasites can significantly interfere with the levels of some antioxidant trace elements and vitamins during caprine coccidiosis. These changes indicate the overproduction of oxidative radicals during the pathogenesis of Eimeria species that may account for extensive oxidative damage in infected animals.
\end{abstract}

\section{Introduction}

Coccidiosis (Eimeriosis sensu stricto) of small ruminants caused by Eimeria species is an intracellular protozoan infection which develops in the small and the large intestines of young animals in particular. Infection of sheep and goats with the Eimeria species is common, especially in lambs and kids, and has a worldwide distribution. ${ }^{1}$ The disease may affect $100 \%$ of goat kids within the age range of 4-10 weeks, and cause severe economic losses by affecting animal health and profitability of the goat industry. ${ }^{2}$

The biological systems in aerobic organ- isms are under the continuous influence of free radicals and reactive oxygen species (ROS)..$^{3}$ Although these radicals are normally neutralized by the antioxidant molecules in body cells, previous investigations showed that the balance between free radicals and antioxidants may be disrupted in many diseases. ${ }^{4}$ In a number of studies, it has been demonstrated that in the cells of hosts infected with different species of parasites, the amount of reactive oxygen radicals which cause lipid peroxidation increased, thereby causing cell and tissue damage.5,6 Despite these results, the status of antioxidant defense system has not been described in the parasitic diseases such as coccidiosis.

Antioxidant agents have been classified as enzymatic and non-enzymatic antioxidants. Non-enzymatic antioxidants involve a variety of free radical quenchers such as metal-binding proteins (transferrin, ceruloplasmin, and albumin), vitamins (A, E and $\mathrm{C}$ ), thiols and micronutrients. The trace elements essentially act as cofactors for antioxidant enzymes involved in the destruction of toxic free radicals produced in the body as a normal consequence of the metabolic processes. ${ }^{7}$ Zinc, copper and selenium are utilized for the synthesis of some antioxidant enzymes including SOD and GPx. The antioxidant trace elements in ruminant coccidiosis have not been clearly investigated; however, there are a few reports on determination of the effects of dietary trace minerals supplements on the oxidative damages due to the Eimeria infections in chickens. 8,9 Vitamins A, E and C may exert their beneficial effects because of their antioxidant, membrane stabilizing, and immunomodulating properties in animals exposed to stresses and infection pressures. Vitamin E has also been extensively evaluated as an antioxidant micronutrient. 10

Ceruloplasmin (Cp) is an alpha2 globulin synthesized primarily in the liver. The antioxidant ceruloplasmin is a copper-containing ferroxidase that can oxidize ferrous iron $\left(\mathrm{Fe}^{2+}\right)$ to its nontoxic ferric $\left(\mathrm{Fe}^{3+}\right)$ form. Ferrous iron $\left(\mathrm{Fe}^{2+}\right)$ is highly damaging because of its ability to generate toxic free radicals. ${ }^{11}$ In fact, $\mathrm{Cp}$ also serves as a general antioxidant by catalyzing the destruction of oxygen radicals. Despite the antioxidant properties of vitamins $\mathrm{A}, \mathrm{E}$ and $\mathrm{C}$ and ceruloplasmin being proved in previous studies, there is no information on the changes of this agent in coccidiosis of ruminants.

Unfortunately, not enough data regarding coccidiosis in ruminants could be traced in the available literature to describe the pattern of antioxidant trace elements, vitamins and ceruloplasmin in the course of the disease. Therefore, our experiment was conducted to elucidate further aspects of non-enzymatic antioxidant system in goats infected with
Correspondence: Saeed Nazifi, Department of Clinical Studies, School of Veterinary Medicine, Shiraz University, Shiraz, P.0. Box: 1731- 71345, Iran.

Tel.: +98.711.228.6940 - Fax: +98.711 .228 .6950 .

E-mail: nazifi@shirazu.ac.ir

Key words: caprine coccidiosis, Eimeria, antioxidant micronutrients, antioxidant vitamins, ceruloplasmin.

Acknowledgements: the authors would thank the Research Council of Shiraz University and School of Veterinary Medicine, Shiraz University for financial and technical support of this study (Grant No.71-GR-VT-5).

Contributions: the authors contributed equally.

Conflict of interests: the authors declare no potential conflict of interests.

Received for publication: 27 June 2014.

Revision received: 29 July 2014.

Accepted for publication: 30 July 2014 .

This work is licensed under a Creative Commons Attribution NonCommercial 3.0 License (CC BYNC 3.0).

(C) Copyright E. Rakhshandehroo et al., 2014

Licensee PAGEPress srl, Italy

Veterinary Science Development 2014; 4:5533

doi:10.4081/vsd.2014.5533

Eimeria parasites.

\section{Materials and Methods}

\section{Preparation of the infectious oocysts}

From January to April 2012, several distinct small ruminant rearing areas were inspected to find out cases of clinical coccidiosis. Among animals, kids with clinical symptoms of the disease (mainly light-green diarrhea) as well as Eimeria positive fecal samples were selected. Some amounts of oocyst containing feces (approximately 5 grams) of each animal were collected, filtered and placed into a shallow layer of $2.5 \%(\mathrm{w} / \mathrm{v})$ potassium dichromate solution in separate Petri dishes. The sporulation of oocysts was achieved by leaving the suspensions in wet chamber $\left(26-28^{\circ} \mathrm{C}\right)$ and stirring the oocyst suspensions daily to infuse oxygen. After a duration of about 1 month (and ensuring more than $90 \%$ of oocysts were sporulated), the contents of all Petri dishes were mixed to form the main stock and stored at $4^{\circ} \mathrm{C}$. The suspension was freed of potassium dichromate solution by serial washing with normal saline. 


\section{Parasitological measurements}

The sporulated oocysts were counted per $1.0 \mathrm{~mL}$ of stock solution using the hemocytometer method as described earlier. ${ }^{12}$ The species identification of oocysts was performed based on sporulation time and morphological characteristics (size, shape, color, shape index, presence or absence of micropyle and its cap, presence or absence of residual, polar and stieda bodies) of the oocysts and sporocysts under $400 \times$ magnifications as in previous studies. 13 The species and the proportion of Eimeria oocysts in stock suspension were $E$. caprina $(65 \%), E$. ninakohlyakimovae (33\%) and $E$. arloingi $(2 \%)$, which were the most pathogenic species. ${ }^{13}$

\section{Experimental design}

Twenty newborn Iranian crossbred kids were selected from a non-infected area at the ages of 1-5 days. The kids were reared artificially under parasite-free conditions in individual cages and fed with a milk replacer. All kids remained uninfected for 14 days and were subjected to routine parasitological tests to ensure lack of prior infections. Ten kids (diseased group) were infected by oral inoculation of $2 \times 10^{3}$ sporulated oocysts per each animal. The other kids remained uninfected as control.

\section{Animal ethics}

This experiment was accomplished under the approval of the state committee on animal ethics, Shiraz University, Iran. Also, we used the recommendations of European Council Directive (86/609/EC) of November 24, 1986, regarding the standards in the protection of animals used for experimental purposes.

\section{Sample preparation and fecal examination}

Blood samples were taken from the jugular vein into plain tubes without anticoagulant at 0 (before inoculation), 3, 7, 14, 17, 21, 24, 28 and 35 days post infection (dpi). Sera were separated from blood samples by centrifugation at $3000 \mathrm{rpm}$ for $10 \mathrm{~min}$ and were kept at $-20^{\circ} \mathrm{C}$ until analyzed.

\section{Trace elements measurement}

The samples with hemolysis were discarded. Digestion of serum was performed by a mixture of perchloric and nitric acid (3:7 ratios respectively). Copper, zinc, iron, manganese and selenium were measured using an atomic absorption spectrophotometer (Shimadzo AA-670, Kyoto, Japan). Argon was used as the purging gas. The background absorption was automatically corrected by the Zeeman effect. One thousand micrograms per milliliter standard solutions of each mineral were used in the measurements. ${ }^{14,15}$

\section{Antioxidant vitamins}

The concentrations of vitamins $\mathrm{A}, \mathrm{E}$ and $\mathrm{C}$ were evaluated by application of the HPLC method using Ultraviolet detection. Vitamins $\mathrm{A}$ and $\mathrm{E}$ were measured based on the protocol described by Johnson-Davis et al.16 and vitamin $\mathrm{C}$ by a Commercial Kit (ALPCO Diagnostics, USA). The HPLC system used consisted of a solvent delivery pump (JASCO 980-PU, Tokyo, Japan), a reversed-phase column (Luna C18, 250×4.6 mm; Phenomenex, CA, USA), and a UV-Vis detector (Jasco, UV975, Tokyo, Japan).

\section{Ceruloplasmin concentration}

The activity of ceruloplasmin (Cp) in serum was measured calorimetrically by the method of Sunderman and Nomoto. ${ }^{17}$

\section{Statistical analysis}

Student's $t$ test was applied to find out the statistical differences between the values measured in the diseased and control groups. The repeated measures ANOVA and Tukey tests were applied for the statistical assessment in each group during the period of the study. All values were expressed as mean and
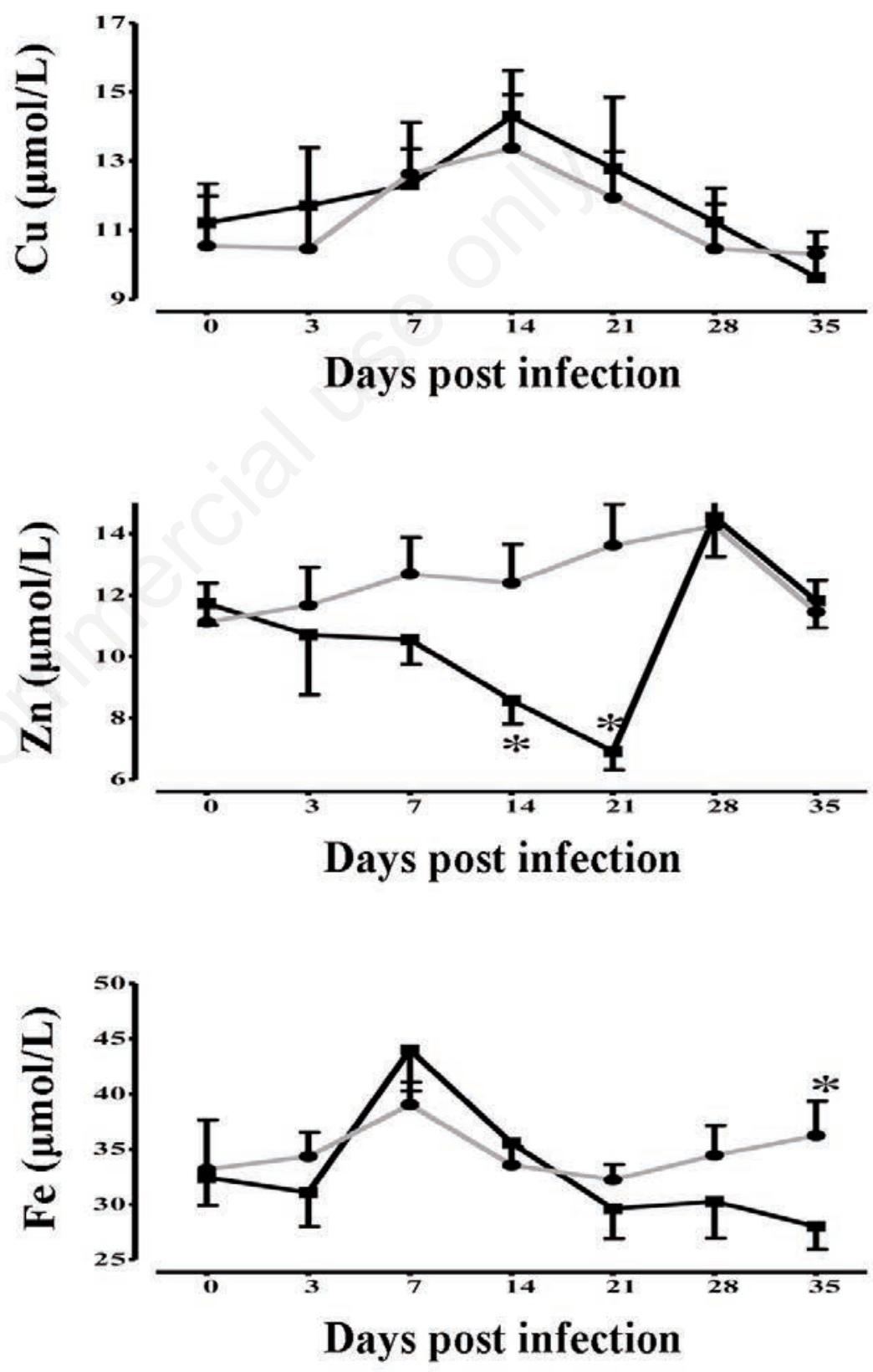

Figure 1. Pattern of changes in antioxidant trace elements (Copper, Zinc, Iron) in noninfected (control, $\bullet$ ) and Eimeria-infected (•) kids in various blood sampling intervals (day). Values are expressed as mean \pm standard error. ${ }^{*}$ Significant differences $(P<0.05)$ between two groups for days post infection indicated. 
standard error of mean (SEM) and the level of significance was set at $\mathrm{P}<0.05$.

\section{Results}

The status of changes in the antioxidant trace elements (copper, zinc, iron, manganese and selenium) in both groups in various blood samplings is shown in Figure 1 and Table 1. Our results revealed that copper showed no significant changes in both groups. In contrast, the serum level of zinc started a mild decrease at $7 \mathrm{dpi}$ and then a remarkable drop at $14 \mathrm{dpi}$. The level of zinc substantially decreased again at 21 dpi $(\mathrm{P}<0.01)$ and reached to the minimum concentration (about half of control values) at this point, then, suddenly increased and no significant difference was seen from 28 dpi to $35 \mathrm{dpi}$. Also, the level of zinc in the infected animals was significantly lower at $21 \mathrm{dpi}$ than that of $14 \mathrm{dpi}$. The concentration of iron in both groups revealed an almost similar pattern of changes as seen in copper. No significant change was observed in infected animals; however, a significant increase $(\mathrm{P}=0.04)$ was evident in the level of iron at the last blood sampling ( $35 \mathrm{dpi}$ ), at which point the iron concentration lowered by 23 percent compared to that of controls.

According to our data, marked decreases were recorded in the serum concentrations of manganese and selenium in the diseased kids. At 3 dpi, the level of manganese revealed a moderate reduction $(\mathrm{P}=0.08)$ and then remarkably reduced to about 75.6, 55.8, 48.7 and 77.8 percent of the controls at $7,14,21$ and $28 \mathrm{dpi}$, respectively. The maximum reduction in the level of manganese was at $21 \mathrm{dpi}$. Also, the level of manganese in the infected animals was significantly lower at 21 dpi than at 14 and $28 \mathrm{dpi}$.

Selenium level decreased substantially at 14 and 21 dpi $(\mathrm{P}<0.01)$ and then gradually increased to the normal (control) values at 21 dpi. The minimum concentration of selenium was at $21 \mathrm{dpi}$ ( 63 percent of the controls). In addition, the level of selenium in the infected group was significantly lower at $21 \mathrm{dpi}$ than at 14 dpi.

The pattern of changes in the serum level of antioxidant vitamins (A, E and C) in both groups in various blood samplings is presented in Figure 2. Interestingly, no significant changes occurred in the concentrations of such vitamins in the serum of the diseased animals throughout the study; however, the level of vitamin $\mathrm{C}$ in the infected kids showed a moderately significant decrease $(\mathrm{P}=0.08)$ at $14 \mathrm{dpi}$ and then reached the minimum level (about 67.5 percent of the control values) at 21 dpi $(\mathrm{P}<0.01)$. Moreover, the level of this vitamin in the infected group showed no significant changes at $21 \mathrm{dpi}$ compared to $14 \mathrm{dpi}$.

The pattern of changes in the serum level of $\mathrm{Cp}$ in non-infected and the Eimeria-infected kids in various blood samplings is depicted in Figure 3. Compared to the control group, obvious elevations $(\mathrm{P}<0.01)$ were seen in the concentrations of $\mathrm{Cp}$ at 14, 21 and $28 \mathrm{dpi}$. The maximum level of $\mathrm{Cp}$ was observed at $21 \mathrm{dpi}$, where it reached to about 3 times (the highest level) that of the controls.

\section{Discussion and Conclusions}

Our results showed significant changes in the serum level of non-enzymatic antioxidant agents including selenium, manganese, vitamin $\mathrm{C}$ and ceruloplasmin during the Eimeriainfection in goats. This implies that the parasites can significantly interfere with the level of some antioxidant trace elements and vitamins during caprine coccidiosis. On the other hand, it can be postulated that these changes are in fact indicators of extensive oxidative
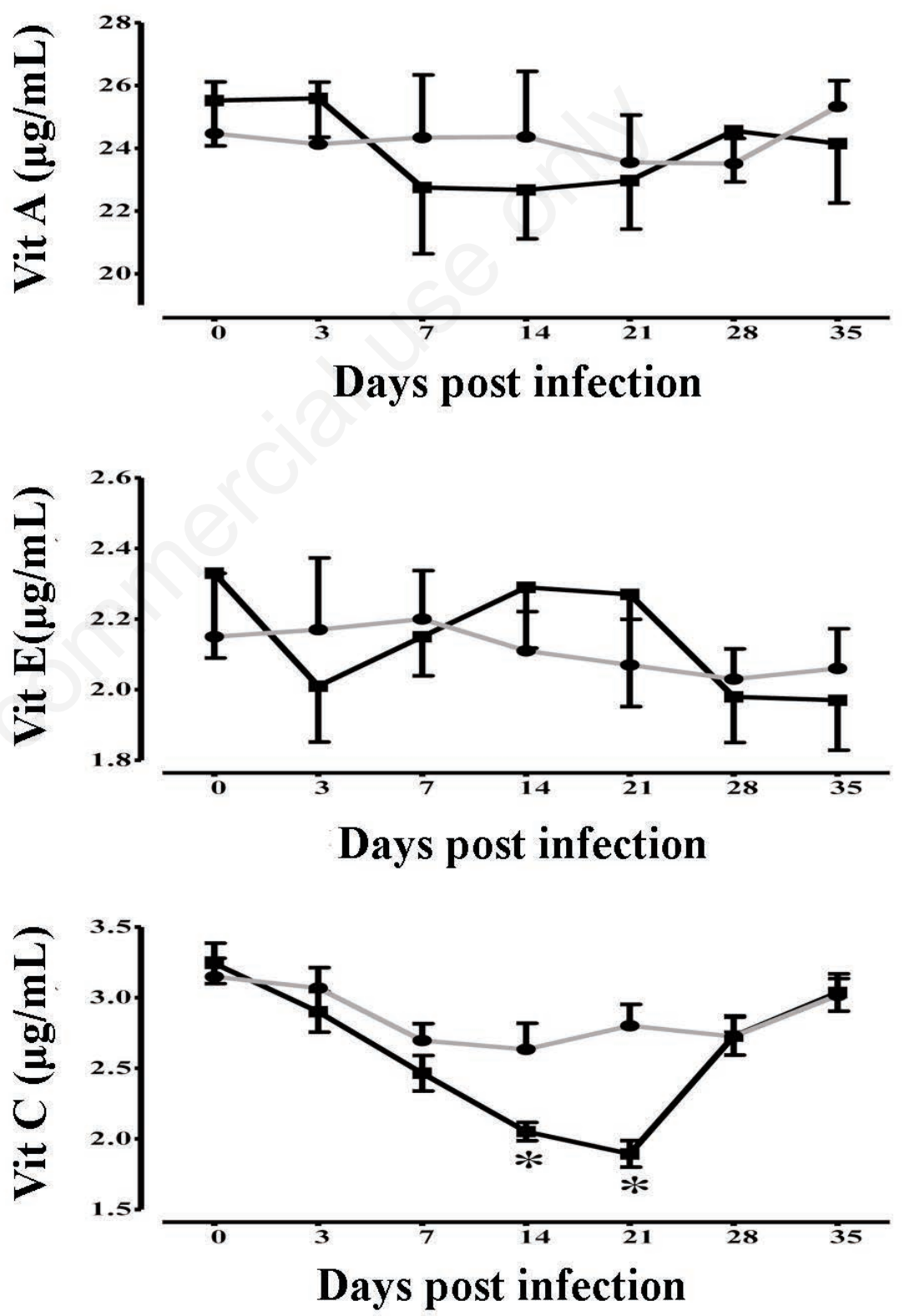

Figure 2. Pattern of changes in antioxidant vitamins in non-infected (control, •) and Eimeria-infected (-) kids in various blood sampling intervals (day). Values are expressed as mean \pm standard error. ${ }^{*}$ Significant differences $(P<0.05)$ between two groups for days post infection indicated. 
injuries that occurred during the pathogenesis of Eimeria parasites. Although, we can achieve this conclusion according to our data, we should consider some limitations such as days which blood taking was accomplished. Obviously, our conclusion could be more rational when we could assay more blood samples in more days after the infection.

Investigation of the pattern of antioxidant trace elements revealed no significant alterations in the serum levels of copper $(\mathrm{Cu})$ and iron $(\mathrm{Fe})$ in infected goats. In contrast, significant decreases have occurred in the concentrations of zinc ( $\mathrm{Zn})$, manganese $(\mathrm{Mn})$ and selenium (Se) mainly from 14 to $21 \mathrm{dpi}$. Micronutrients such as copper, zinc, manganese, and selenium (Se) participate in a wide variety of physiological processes of animals. ${ }^{18}$ They are also essential for catalytic activity and proper spatial conformation of antioxidant enzymes such as superoxide dismutase (SOD), catalase, and glutathione peroxidase (GSH-Px) and thereby play important roles in the antioxidant defense and lipid peroxidation. ${ }^{19}$ In addition, iron also functions as a component of some metalloenzymes such as SOD in the form of Fe-SOD isoenzyme, ${ }^{20}$ that take part in reduction reactions. Collectively, it can be argued that decreased level of trace elements in the serum of the infected goats in this study obviously represents their coordinated antioxidant role accompanied by antioxidant enzymes activities. In other words, trace minerals including $\mathrm{Zn}, \mathrm{Mn}$ and Se could have a considerable role in sustaining the antioxidant responses against the oxidative damages triggered by the infection with Eimeria. Here, one question was arisen that state whether the rate of milk uptake in the diseased kids may have a remarkable effect on the serum concentrations of $\mathrm{Zn}, \mathrm{Mn}$ and Se. To overcome this problem, all kids, either controls or diseased, were fed with an approximately similar rates of milk. Our data also proved that despite the structural role of $\mathrm{Cu}$ and $\mathrm{Fe}$ in the antioxidant metalloenzymes, they did not induce significant effects on the antioxidant defense against the parasites. In addition, the unchanged level of these minerals in our study may be attributed to the occurrence of equilibrium between the level of their uptake by the diet and their level in the serum and body tissues, particularly in the liver storage and its consumption to form antioxidant enzymes. The antioxidant trace elements in ruminant coccidiosis have not been clearly investigated and no documented report exists to show the pattern of these elements during the disease; however, there are a few reports on determination of the effects of dietary trace minerals supplements on the oxidative damages due to the Eimeria infections in chickens. For example, Georgieva et al. ${ }^{8}$ analyzed the effects of dietary supplements of $\mathrm{Zn}$ on the antioxidant status in chickens experimentally infected with Eimeria acervulina. Besides corroborating the oxidative stress in the infected chickens, their results proved the ameliorating role of $\mathrm{Cu} \mathrm{Zn}(\mathrm{OH}) 3 \mathrm{Cl}(0.170 \mathrm{~g}$ per $\mathrm{kg}$ food) against $E$. acervulina-induced oxidative damage in infected chickens.

Regarding the unchanged levels of antioxidant vitamins $A$ and $E$ on the one side and the significant decrease in serum level of vitamin $\mathrm{C}$ from 14 to $21 \mathrm{dpi}$ on the other, it can be suggested that despite the antioxidant activity of vitamins $\mathrm{A}$ and $\mathrm{E}$, these vitamins could not indicate marked responses to oxidative injuries induced by the parasites in diseased kids. In contrast, vitamin $\mathrm{C}$ may indicate a sig- nificant role to protect the cells from the invasion of free radicals. It can be proposed that despite cellular protective action of vitamins against oxidative stress as a result of parasitic invasions, ${ }^{21}$ the unchanged level of vitamins A and $\mathrm{E}$ in our work may be attributed to the occurrence of an equilibrium between the levels of vitamin uptake and their levels in the serum and body tissues, particularly the liver storage which probably has a role in enhancing the decreased serum level of these vitamins in infected goats. Although the status of antioxidant vitamins has not been clearly investigated in ruminant coccidiosis, a number of previous studies which studied the hemoparasitic diseases (such as the genus Babesia) demonstrate the decreased blood levels of such vitamins in the serum of the affected animals and suggest that this phenomenon was a consequence of elevation in the level of oxidative damages, ${ }^{22-24}$ however, Nazifi et al. 25 investigated the status of antioxidant vitamins (A, E and C) in sheep infected with Theileria lestoquardi and concluded no statistical differences in the level of these vitamins in the diseased sheep compared to the controls. Obvious elevations were observed in the serum concentrations of $\mathrm{Cp}$ in

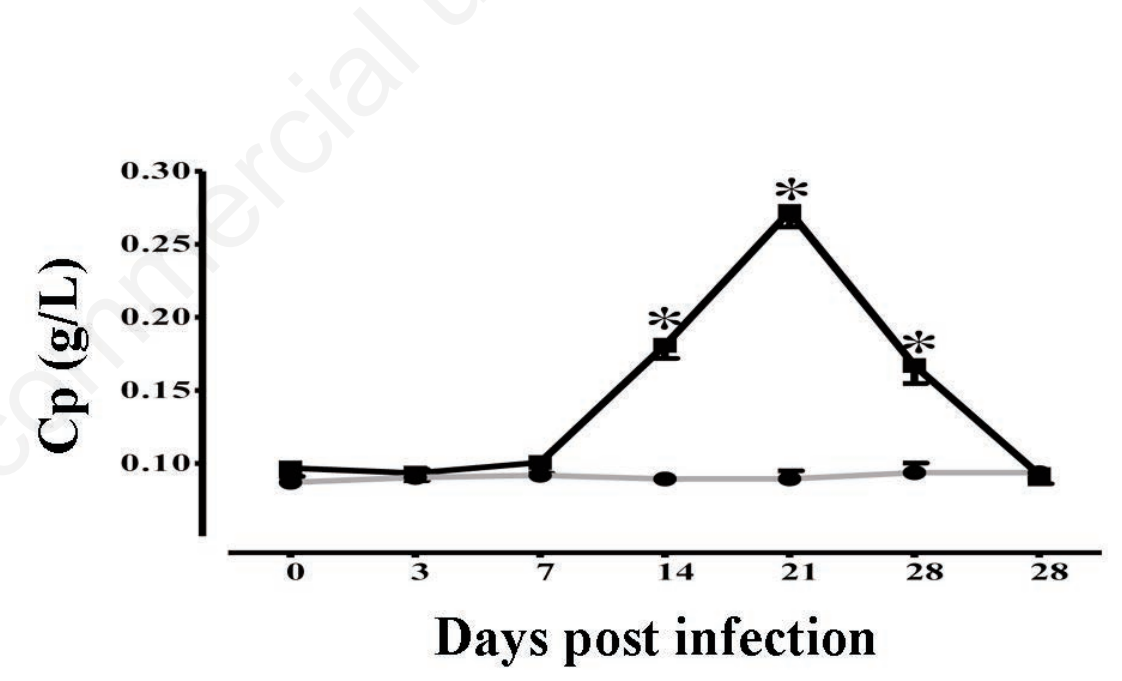

Figure 3. Pattern of changes in the concentration of ceruloplasmin $(\mathrm{Cp})$ in non-infected (control, •) and Eimeria-infected (•) kids in various blood sampling intervals (day). Values are expressed as mean \pm standard error. ${ }^{*}$ Significant differences $(\mathrm{P}<0.05)$ between two groups for days post infection indicated.

Table 1. Changes in antioxidant trace elements (Manganese and Selenium, Mn and Se) in non-infected (control) and Eimeria-infected (diseased) kids in various blood sampling intervals (days post infection). Values are expressed as mean \pm standard error.

\begin{tabular}{|c|c|c|c|c|c|c|c|c|}
\hline & & 0 & 3 & 7 & 14 & 21 & 28 & 35 \\
\hline $\mathrm{Mn}$ & $\begin{array}{l}\text { Control } \\
\text { Diseased }\end{array}$ & $\begin{array}{l}50.86 \pm 1.33 \\
50.24 \pm 1.76\end{array}$ & $\begin{array}{c}46.94 \pm 1.38 \\
43.8 \pm 0.89\end{array}$ & $\begin{array}{c}46.46 \pm 2.51 \\
35.12 \pm 1.38^{*}\end{array}$ & $\begin{array}{c}49.46 \pm 1.66 \\
27.59 \pm 1.66^{*}\end{array}$ & $\begin{array}{c}47.26 \pm 1.79 \\
23.01 \pm 0.62 *\end{array}$ & $\begin{array}{c}47.16 \pm 1.73 \\
36.69 \pm 0.59 *\end{array}$ & $\begin{array}{l}45.01 \pm 1.62 \\
44.34 \pm 1.18\end{array}$ \\
\hline Se & $\begin{array}{l}\text { Control } \\
\text { Diseased }\end{array}$ & $\begin{array}{l}2.45 \pm 0.06 \\
2.39 \pm 0.07\end{array}$ & $\begin{array}{l}2.27 \pm 0.05 \\
2.27 \pm 0.04\end{array}$ & $\begin{array}{l}2.05 \pm 0.04 \\
1.95 \pm 0.05\end{array}$ & $\begin{array}{c}2.2 \pm 0.08 \\
1.67 \pm 0.05^{*}\end{array}$ & $\begin{array}{c}2.26 \pm 0.07 \\
1.43 \pm 0.05 *\end{array}$ & $\begin{array}{c}2.03 \pm 0.05 \\
2.1 \pm 0.02\end{array}$ & $\begin{array}{l}2.35 \pm 0.02 \\
2.25 \pm 0.05\end{array}$ \\
\hline
\end{tabular}

*Significant differences $(\mathrm{P}<0.05)$ between two groups for dpi indicated. 
infected kids as the maximum level of $\mathrm{Cp}$ was at $21 \mathrm{dpi}$ where it reached to about 3 times that of the controls. $\mathrm{Cp}$ is generally an acutephase glycoprotein and the principal carrier of copper in plasma, is thought to be an effective antioxidant for a variety of radicals and has a potent peroxidase activity to decompose hydrogen peroxide in the presence of reduced glutathione. $\mathrm{Cp}$ also inhibits the peroxidase activity of myeloperoxidase in a concentration-dependent manner. ${ }^{26}$ Therefore, the significant increase in the concentration of $\mathrm{Cp}$ in infected goats can be attributed to the host response against oxidative stress. It can be postulated that along with the pathogenicity of the Eimeria and the production of a large volume of free radicals which lead to the oxidative damage, the synthesis of $\mathrm{Cp}$ in the liver would be promoted in order to neutralize the hazards of the oxidative condition.

Taken together, the infection with the pathogenic species of Eimeria in goats can provoke significant modulations in the level of some antioxidant trace elements, some antioxidant vitamins and ceruloplasmin during the establishment of the parasites. These changes can be assigned as the indicators of overproduction of oxidative radicals which led to extensive oxidative injuries during the pathogenesis of Eimeria parasites.

\section{References}

1. Wang CR, Xiao JY, Chen AH, et al. Prevalence of coccidial infection in sheep and goats in northeastern China. Vet Parasitol 2010;174:213-7.

2. Koudela B, Boková A. Coccidiosis in goats in the Czech Republic. Vet Parasitol 1998;76:261-7.

3. Tappel A, Tappel A. 0xidant free radical initiated chain polymerization of protein and other biomolecules and its relationship to diseases. Med Hypotheses 2004;63:98-9.

4. Abd Ellah MR. Involvement of free radicals in animal diseases. Comp Clin Pathol 2010;19:615-9.

5. Sarin K, Kumar A, Prakash A, Sharma A. Oxidative stress and antioxidant defence mechanism in Plasmodium vivax malaria before, after chloroquin treatment. Ind $\mathrm{J}$ Malariol 1993;30:127-33.

6. Smith NC, Bryant C. Free radical generation during primary infections with Nippostrongylus brasiliensis. Parasite Immunol 1989;11:147-60.

7. Halliwell B. Free radicals, antioxidants, and human disease: curiosity, cause, or consequence. Lancet 1994;344:721-4.

8. Georgieva NV, Gabrashanska M, Koinarski N, Yaneva Z. Zinc supplementation against Eimeria acervulinaInduced Oxidative Damage in Broiler Chickens. Vet Med Int 2011;2011:647124.

9. Jafari RA, Kiani R, Shahryari A, et al. Effect of dietary vitamin $\mathrm{E}$ on plasma oxidative stress in broiler chicks infected with Eimeria tenella. Comp Clin Pathol 2012;21:895-9.

10. Rice-Evans CA, Diplock AT. Current status of antioxidant therapy. Free Radic Biol Med 1993;15:77-96.

11. Patel BN, Dunn RJ, Jeong SY, et al. Ceruloplasmin regulates iron levels in the CNS and prevents free radical injury. $\mathrm{J}$ Neurosci 2002;22:6578-86.

12. Holdsworth PA, Conway DP, McKenzie $\mathrm{ME}$, et al. World association for advancement of veterinary parasitology (WAAVP) guidelines for evaluating the efficacy of anticoccidial drugs in chickens and turkeys. Vet Parasitol 2004;121:189-212.

13. Jalila A, Dorny P, Salim NB, Vercruysse J. Coccidiosis infections of goats in Selangor, Peninsular Malaysia. Vet Parasitol 1998;74:165-72.

14. Aihara K, Nishi Y, Hatano S, et al. Zinc, copper, manganese, and selenium metabolism in thyroid disease. Am J Clin Nutr 1984;40:26-35.

15. Bouman AA, Platenkamp AJ, Posma FD. Determination of cobalt in urine by flameless atomic absorption spectroscopy. Comparison of direct analysis using Zeeman background correction and indirect analysis using extraction in organic solution. Ann Clin Biochem 1986;23:34650.

16. Johnson-Davis KL, Moore SJ, Owen WE, et al. A rapid HPLC method used to establish pediatric reference intervals for vitamins $A$ and E. Clin Chim Acta 2009;405:35-8.
17. Sunderman FW Jr., Nomoto S. Measurement of human serum ceruloplasmin by its p-phenylenediamine oxidase activity. Clin Chim ca Acta 1970; 160:903-7.

18. Richards JD, Zhao J, Harrell RJ, et al. Trace mineral nutrition in poultry and swine. Asian Austral J Anim Sci 2010;23:1527-34.

19. Barandier C, Tanguy S, Pucheu S, et al. Effect of antioxidant trace elements on the response of cardiac tissue to oxidative stress. Ann N Y Acad Sci 1999;874:138-55.

20. Bannister JV, Bannister WH, Rotills G. Aspects of the structure, function and application of superoxide dismutase. CRC Crit Rev Biochem 1987;22:111-80.

21. Dede S, Deger Y, Deger S, Alkan M. Determination of the status of lipid peroxidation and antioxidants in sheep infected with certain endoparasites (Fasciola sp, Trichostrongylidae sp., Eimeria sp.). Acta Parasitol Turcica 2000;24:190-3.

22. Deger S, Deger Y, Bicek K, et al. Status of lipid peroxidation, antioxidants, and oxidation products of nitric oxide in equine babesiosis: status of antioxidant and oxidant in equine babesiosis. $\mathrm{J}$ Equine Vet Sci 2009;29:743-7.

23. Bicek K, Deger Y, Deger S. Some biochemical and haematological parameters of sheep infected with Babesia species. YYU Veterinary Fakultesi Dergisi 2005; 16:33-5.

24. Dede S, Deger Y, Kahraman T, et al. Oxidation products of nitric oxide and the concentrations of antioxidant vitamins in parasitized goats. Acta Vet Brno 2002;71: 341-5.

25. NazifiS, Razavi SM, Rakhshandehroo E, et al. Ovine malignant theileriosis: the status of antioxidant vitamins, serum lipid profile, lipid peroxidation and erythrocyte antioxidant defense. Comp Clin Pathol 2013;22:379-85.

26. Park YS, Suzuki K, Mumby S, et al. Antioxidant binding of caeruloplasmin to myeloperoxidase: Myeloperoxidase is inhibited, but oxidase, peroxidase and immunoreactive properties of ceruloplasmin remain intact. Free Rad Res 2000;33:261-5. 